\title{
Optimization of Curing Regimes for Precast Prestressed Members with Early-Strength Concrete
}

\author{
Songhee Lee ${ }^{1)}$, Ngocchien Nguyen ${ }^{1)}$, Thi Suong Le ${ }^{1)}$, and Chadon Lee ${ }^{2), *}$
}

(Received March 15, 2016, Accepted May 24, 2016, Published online June 28, 2016)

\begin{abstract}
Early-strength-concrete (ESC) made of Type I cement with a high Blaine value of $500 \mathrm{~m}^{2} / \mathrm{kg}$ reaches approximately $60 \%$ of its compressive strength in 1 day at ambient temperature. Based on the 210 compressive test results, a generalized rateconstant material model was presented to predict the development of compressive strengths of ESC at different equivalent ages $(9$, $12,18,24,36,100$ and $168 \mathrm{~h})$ and maximum temperatures $\left(20,30,40,50\right.$ and $\left.60{ }^{\circ} \mathrm{C}\right)$ for design compressive strengths of 30,40 and $50 \mathrm{MPa}$. The developed material model was used to find optimum curing regimes for precast prestressed members with ESC. The results indicated that depending on design compressive strength, conservatively $25-40 \%$ savings could be realized for a total curing duration of $18 \mathrm{~h}$ with the maximum temperature of $60{ }^{\circ} \mathrm{C}$, compared with those observed in a typical curing regime for concrete with Type I cement.
\end{abstract}

Keywords: curing, temperature, compressive strength, concrete.

\section{Introduction}

Steam curing process is used in the fabrication of precast, prestressed members in plants to improve production efficiency and quality control and to attain a sufficient concrete compressive strength to transfer the prestress within the turnover period. A 24-h turnover period is considered for most structural members. In general, it consists of a preliminary work period for cleaning, tensioning and casting of concrete, followed by a delay period for initial setting of concrete at ambient temperature. Temperature is then elevated, maintained at maximum temperature, and lowered, followed by a cooling period and a posterior period for demolding, cutting and transportation of concrete members (Hanson 1963; ACI 517.2-2R-87 1992; Ramezanianpour et al. 2013). Although steam curing can effectively increase the early-age strength of concrete in addition to other material properties and hence improve production efficiency, it increases the fabrication cost due to the consumption of fuel. In addition, steam curing emits a large amount of carbon dioxide, which could lead to environmental issues.

A few efforts have been made to find appropriate steam curing regimes based on the experimental observation of the

\footnotetext{
${ }^{1)}$ Architectural Engineering, Graduate School, ChungAng University, Seoul 156-756, Republic of Korea.

${ }^{2)}$ School of Architecture and Building Science, College of Engineering, Chung-Ang University, Seoul 156-756, Republic of Korea.

*Corresponding Author; E-mail: cdlee@cau.ac.kr Copyright ( $\odot$ The Author(s) 2016. This article is published with open access at Springerlink.com
}

development of compressive strength of cylindrical or cubical concrete specimens cured under different steam curing regimes. Erdogdu and Kurbetci (1998) suggested the maximum temperature of $80{ }^{\circ} \mathrm{C}$ for $10 \mathrm{~h}$ for concrete with Type I cement. Hwang et al. (2012) recommended an optimum 18-h steam curing regime with delay period of $5 \mathrm{~h}$ and the maximum temperature of $60{ }^{\circ} \mathrm{C}$ to accelerate early-age strength for self-consolidating concrete (SCC) made of different combinations of CSA type cement, Class F fly ash and silica fume. Ramezanianpour et al. (2013) suggested an optimum steam curing cycle at the maximum temperature of $60{ }^{\circ} \mathrm{C}$ for $10 \mathrm{~h}$, with an extra 3-h preheating for SCC made of Type II cement.

When the Blaine value of Type I cement increases, hydration is accelerated and the rapid development of compressive strength can be achieved in early-stage curing (Schindler and Folliard 2005; Sajedi and Razak 2011). Type I cement with the Blain value of $500 \mathrm{~m}^{2} / \mathrm{kg}$ (semi-high-early-strength cement or SHESC, hereafter) is used in this study, which has the same chemical components as standard Type I cement but has a greater Blaine value, as compared to $350 \mathrm{~m}^{2} / \mathrm{kg}$ for standard Type I cement. The most beneficial aspect of ESC made with SHESC versus ordinary concrete made with standard Type I cement is its rapid development of compressive strength. At ambient temperature of $20^{\circ} \mathrm{C}$, compressive strength of ESC made with SHESC reaches approximately 60 and $100 \%$ of its design compressive strength $\left(f_{\text {cd }}^{\prime}\right)$ in one and 7 days, respectively. Because of the accelerated development of compressive strength, the use of SHESC with a reduced curing regime, compared to the use of normal strength concrete with Type I cement, could reduce fuel consumption and carbon dioxide emission. The objective of this study is to find optimally reduced curing regimes for the use of SHESC in producing precast prestressed ESC members. 


\section{Experiments}

\subsection{Mix Proportions}

Compressive tests of ESC were performed for three different $f_{\text {cd }}^{\prime} \mathrm{s}$ of 30,40 and $50 \mathrm{MPa}$ with target slump of $200 \pm 20 \mathrm{~mm}$ and air content of $3 \pm 1 \%$. Table 1 summarizes mix proportions for the ESC. Crushed gravels with $20 \mathrm{~mm}$ nominal maximum size, specific gravity of $2.6 \mathrm{~g} / \mathrm{cm}^{3}$, and fineness modulus of 6.8 were used. River sand was used as fine aggregates, which had a specific gravity of $2.6 \mathrm{~g} / \mathrm{cm}^{3}$, and fineness modulus of 2.2. Superplasticizer (SP) was used to increase workability.

\subsection{Preparation and Test Results}

Mixing and specimen preparation were carried out at room temperature and humidity of $20 \pm 2{ }^{\circ} \mathrm{C}$ and $50 \pm 5 \%$, respectively. After completing mixing with a 120 -liter-capacity concrete pan mixer, the slump and air content of the fresh concrete were measured according to ASTM C143/ C143M-10 (2010) and ASTM C231/C231M-14 (2014). From the same batch, 14 cylinders of $100 \times 200 \mathrm{~mm}$ were cast. Before submerging them into water for curing, each mold was enclosed in a waterproof plastic bag and the top surface was covered with a plastic sheet to prevent evaporation of the water in the mold. The cylindrical molds were then put into the water in order to cure the ESC according to the pre-determined curing regime (Fig. 1). Portable and manually controllable coiled water heaters were used to adjust water temperature. Thermocouples were used to measure the temperatures at the mid-depth of ESC in the cylindrical mold and water. From the preliminary tests, it was found that the ESC developed 70 and $100 \%$ of its $f_{\mathrm{cd}}^{\prime}$ value at 36 and $168 \mathrm{~h}$ (7 days) after casting, respectively, at ambient temperature of $20{ }^{\circ} \mathrm{C}$. Accordingly, seven different ages of $9,12,18,24,36,100$ and $168 \mathrm{~h}$ at ambient temperature were selected for the measurement of compressive strength.

For each $f_{\text {cd }}^{\prime}$, five different maximum temperatures $\left(T_{\max }\right)$ of $20,30,40,50$ and $60{ }^{\circ} \mathrm{C}$ were considered. As the maximum temperature of $60{ }^{\circ} \mathrm{C}$ has been commonly applied to steam curing fabrication of architectural precast prestressed units in practice, the maximum value of $T_{\max }$ was chosen to be $60{ }^{\circ} \mathrm{C}$ in this study. At temperatures other than $20{ }^{\circ} \mathrm{C}$, equivalent ages ( $t_{\mathrm{eq}}$ in hour) were estimated corresponding to the seven different ages of measurement. The concept of $t_{\mathrm{eq}}$ given in Eq. (1), which was suggested by Freiesleben and Pederson (1977) and also recommended by ASTM C 107404 (2004), was used.

$$
t_{\mathrm{eq}}=\sum_{0}^{t} e^{-\frac{E_{\mathrm{eq}}}{R}\left(\frac{1}{T_{\mathrm{c}}+273}-\frac{1}{T_{\mathrm{r}}+273}\right)} \Delta t
$$

where, $\Delta t$ is the time interval (day), $E_{\text {eq }}$ is the activation energy $(=33,500 \mathrm{~J} / \mathrm{mol})$ used in the estimation of $t_{\text {eq }}, R$ is the universal gas constant $(=8.314 \mathrm{~J} / \mathrm{mol} / \mathrm{K})$ and $T_{\mathrm{c}}=$ temperature of concrete $\left({ }^{\circ} \mathrm{C}\right)$.

Figure 2a illustrates typical curing regimes adopted in this study for the ESC subjected to different $T_{\max }$. A 3-h delay period was assigned for initial setting at the beginning of each curing regime. Then temperature was increased gradually up to $T_{\max }$ and maintained until a $t_{\text {eq }}$ of $36 \mathrm{~h}$, the equivalent age at which the compressive strength of ESC reaches $70 \%$ of $f_{\text {cd }}^{\prime}$. Then the temperature was lowered from $T_{\max }$ to $20{ }^{\circ} \mathrm{C}$ and maintained at that temperature until the total elapsed $t_{\text {eq }}$ became $168 \mathrm{~h}$. For all cases, the rates of temperature increase and decrease of the concrete were chosen to be $10{ }^{\circ} \mathrm{C} / \mathrm{h}$ and $-10^{\circ} \mathrm{C} / \mathrm{h}$, respectively. In Fig. $2 \mathrm{~b}$, the relationships between the $t_{\mathrm{eq}}$ and real elapsed time $(t)$ at strength measurement are presented for each curing regime for a corresponding $T_{\max }$.

Table 1 Mix proportions.

\begin{tabular}{|c|c|c|c|c|c|c|c|c|}
\hline \multirow[t]{2}{*}{${f^{\prime}}_{\mathrm{cd}}(\mathrm{MPa})$} & \multirow[t]{2}{*}{$W / C$} & \multirow[t]{2}{*}{ Slump (mm) } & \multirow[t]{2}{*}{$S /(S+G)$} & \multicolumn{4}{|c|}{ Weight per unit volume $\left(\mathrm{kg} / \mathrm{m}^{3}\right)$} & \multirow[t]{2}{*}{$\mathrm{SP} / \mathrm{C}$} \\
\hline & & & & $W$ & $C$ & $S$ & $G$ & \\
\hline 30 & 0.46 & 200 & 0.38 & 177 & 385 & 644 & 1051 & 0.01 \\
\hline 40 & 0.41 & 200 & 0.37 & 177 & 433 & 606 & 1040 & 0.01 \\
\hline 50 & 0.35 & 200 & 0.36 & 177 & 506 & 570 & 1022 & 0.01 \\
\hline
\end{tabular}

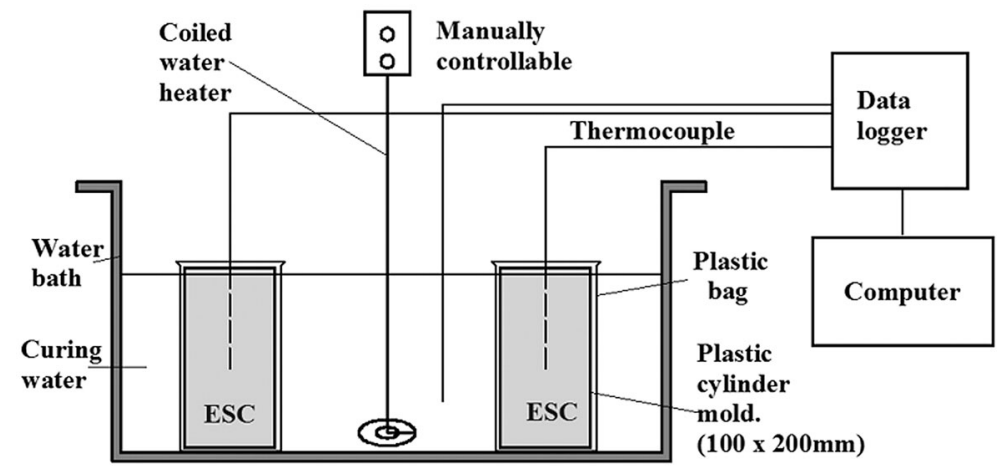

Fig. 1 Curing scheme of ESC in water bath. 

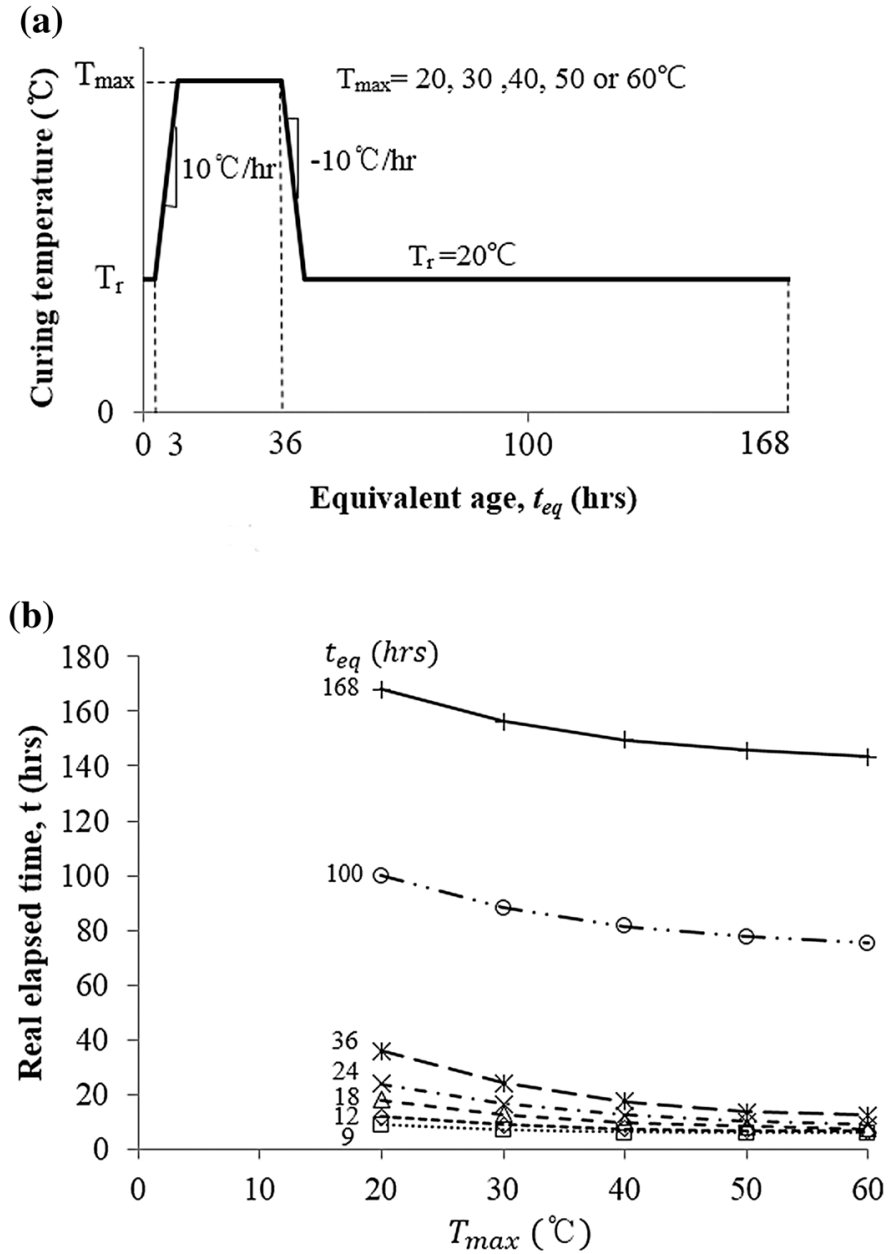

Fig. 2 Curing regimes with 5 different $T_{\max }$ a Typical curing regime, b $T_{\max }$ versus real elapsed time $(t)$ for different equivalent ages $\left(t_{\text {eq }}\right)$.

At each age of measurement, a pair of replica ESC cylinders from the same batch and with the same curing condition were tested in compression. Top surfaces were ground shortly before they were tested in compression with a hydraulic servo-controlled compressive testing machine of $1000 \mathrm{kN}$ capacity. The rate of loading was within the range of $0.25 \pm 0.05 \mathrm{MPa} / \mathrm{s}$. The results of 210 compression tests are given in Table 2. Test specimens were designated in Table 2 as CSn, where $\mathrm{C}$ stands for cylinder, $\mathrm{S}$ for concrete compressive strength $\left(S=L, M\right.$ and $H$ for $f_{\text {cd }}^{\prime}=30,40$ and $50 \mathrm{MPa}$, respectively) and $\mathrm{n}$ for the two-digit $T_{\max }$ in ${ }^{\circ} \mathrm{C}$.

Figure 3 a illustrates the effects of $T_{\max }$ on the development of compressive strength of ESC for the cases with $T_{\max }=20$, 40 and $60{ }^{\circ} \mathrm{C}$. Strength development of the ESC was characterized by a rapid increase during early-stage curing followed by a gradual increase and then asymptotic approach to ultimate strength. Figure $3 \mathrm{a}$ also indicates that higher curing temperature accelerates the rate of hydration of ESC in early-age of curing but results in crossover effect in later-stage. The crossover effect is known to occur due to a retarding effect on the diffusion of the hydrate in the secondary reaction of cement hydration by built-up of hydrate shells of low-permeability hydration products around the cement grains (McIntosh 1956; Alexander and Taplin 1962; Carino and Lew 1981; Kjellsen et al. 1990; Yi et al. 2005). Formation of microcracks and/or coalesce by tensile stress resulting from the difference of volume expansion between water and voids is also known to cause a decrease in strength with an increase in initial curing temperature (Verbeck and Helmuth 1968; Carino and Lew 1981; Kjellsen and Detwiler 1993).

The rate of strength development is presented for different $f_{\mathrm{cd}}^{\prime} s$ in Fig. 3b. A more rapid increase in strength at earlystage curing was observed with higher $f_{\mathrm{cd}}^{\prime}$ under the same $T_{\max }$. At later-stage curing, however, similar rate of strength increase was observed for all $f_{\mathrm{cd}}^{\prime} s$.

\section{An Empirical Model for the Development of Compressive Strength of ESC}

Bernhardt (1956) suggested that the development rate of concrete strength at time $t(S)$ with respect to its limiting strength $\left(S_{\mathrm{u}}\right)$ decreases with the development of compressive strength as given in Eq. (2):

$$
\frac{\mathrm{d}\left(\frac{S}{S_{\mathrm{u}}}\right)}{\mathrm{d} t}=k\left(1-\frac{S}{S_{\mathrm{u}}}\right)^{r}
$$

where, $k$ is the rate constant of concrete $\left(\right.$ day $\left.^{-1}\right)$ and $r$ is the reaction coefficient. 
Table 2 Measured concrete strengths ( $S$ in MPa) at different values of $T_{\max }$ and $t_{\text {eq. }}$.

\begin{tabular}{|c|c|c|c|c|c|c|c|c|c|c|c|c|c|c|c|c|c|}
\hline \multicolumn{2}{|c|}{ Specimens } & \multirow{2}{*}{$\begin{array}{c}f_{\mathrm{cd}}^{\prime} \\
(\mathrm{MPa})\end{array}$} & \multirow{2}{*}{$\begin{array}{l}T_{\max } \\
\left({ }^{\circ} \mathrm{C}\right)\end{array}$} & \multicolumn{14}{|c|}{ Equivalent age, $t_{e q}(\mathrm{~h})$} \\
\hline No. & Name & & & \multicolumn{2}{|c|}{9} & \multicolumn{2}{|c|}{12} & \multicolumn{2}{|c|}{18} & \multicolumn{2}{|c|}{24} & \multicolumn{2}{|c|}{36} & \multicolumn{2}{|c|}{100} & \multicolumn{2}{|c|}{168} \\
\hline 1 & CL20 & 30 & 20 & 0.2 & 0.2 & 1.0 & 0.9 & 9.9 & 9.6 & 18.0 & 14.6 & 23.6 & 24.8 & 34.5 & 33.1 & 40.8 & 39.9 \\
\hline 2 & CL30 & & 30 & 0.6 & 0.4 & 2.6 & 2.8 & 6.2 & 6.2 & 19.0 & 17.8 & 21.1 & 20.8 & 33.6 & 32.2 & 37.4 & 37.2 \\
\hline 3 & CL40 & & 40 & 0.2 & 1.3 & 1.8 & 1.6 & 5.8 & 6.1 & 14.5 & 16.8 & 21.9 & 22.6 & 31.2 & 26.9 & 35.9 & 36.7 \\
\hline 4 & CL50 & & 50 & 0.9 & 1.1 & 3.5 & 3.5 & 8.6 & 9.7 & 12.6 & 15.4 & 21.3 & 21.1 & 32.3 & 31.5 & 36.2 & 33.4 \\
\hline 5 & CL60 & & 60 & 0.2 & 0.4 & 1.5 & 1.5 & 7.7 & 6.3 & 14.3 & 16.9 & 27.8 & 26.3 & 32.6 & 30.5 & 33.2 & 32.7 \\
\hline 6 & CM20 & 40 & 20 & 0.2 & 0.2 & 0.9 & 1.0 & 13.2 & 13.1 & 24.9 & 23.8 & 28.3 & 29.1 & 43.5 & 42.2 & 47.1 & 49.1 \\
\hline 7 & CM30 & & 30 & 0.2 & 0.3 & 3.8 & 2.4 & 15.5 & 13.3 & 24.8 & 22.8 & 29.4 & 30.3 & 40.4 & 35.6 & 46.6 & 47.3 \\
\hline 8 & CM40 & & 40 & 0.4 & 0.5 & 1.8 & 2.0 & 11.2 & 12.0 & 23.4 & 23.8 & 28.5 & 32.4 & 43.3 & 36.2 & 47.7 & 49.4 \\
\hline 9 & CM50 & & 50 & 0.7 & 0.3 & 2.3 & 2.8 & 13.0 & 13.3 & 21.1 & 22.2 & 32.1 & 31.8 & 43.9 & 45.8 & 47.7 & 45.1 \\
\hline 10 & CM60 & & 60 & 0.3 & 0.5 & 2.7 & 3.9 & 11.4 & 13.5 & 23.7 & 22.0 & 30.8 & 31.8 & 40.1 & 38.7 & 47.2 & 43.5 \\
\hline 11 & $\mathrm{CH} 20$ & 50 & 20 & 0.4 & 0.4 & 1.1 & 1.6 & 15.3 & 16.1 & 25.1 & 27.5 & 38.5 & 37.0 & 53.6 & 52.3 & 57.8 & 58.1 \\
\hline 12 & CH30 & & 30 & 0.2 & 0.3 & 1.0 & 1.2 & 16.0 & 17.0 & 25.9 & 24.7 & 32.7 & 35.3 & 49.0 & 51.6 & 58.3 & 57.6 \\
\hline 13 & $\mathrm{CH} 40$ & & 40 & 0.2 & 0.1 & 1.0 & 1.8 & 11.2 & 17.2 & 25.2 & 25.5 & 37.7 & 38.9 & 54.3 & 52.6 & 56.7 & 58.5 \\
\hline 14 & CH50 & & 50 & 0.4 & 0.4 & 1.9 & 4.1 & 15.9 & 15.9 & 28.6 & 28.5 & 35.5 & 35.6 & 47.2 & 46.7 & 53.9 & 56.1 \\
\hline 15 & CH60 & & 60 & 0.2 & 0.2 & 2.3 & 2.1 & 11.5 & 13.3 & 28.4 & 30.1 & 40.1 & 39.0 & 51.5 & 49.6 & 52.2 & 54.0 \\
\hline
\end{tabular}

(a)
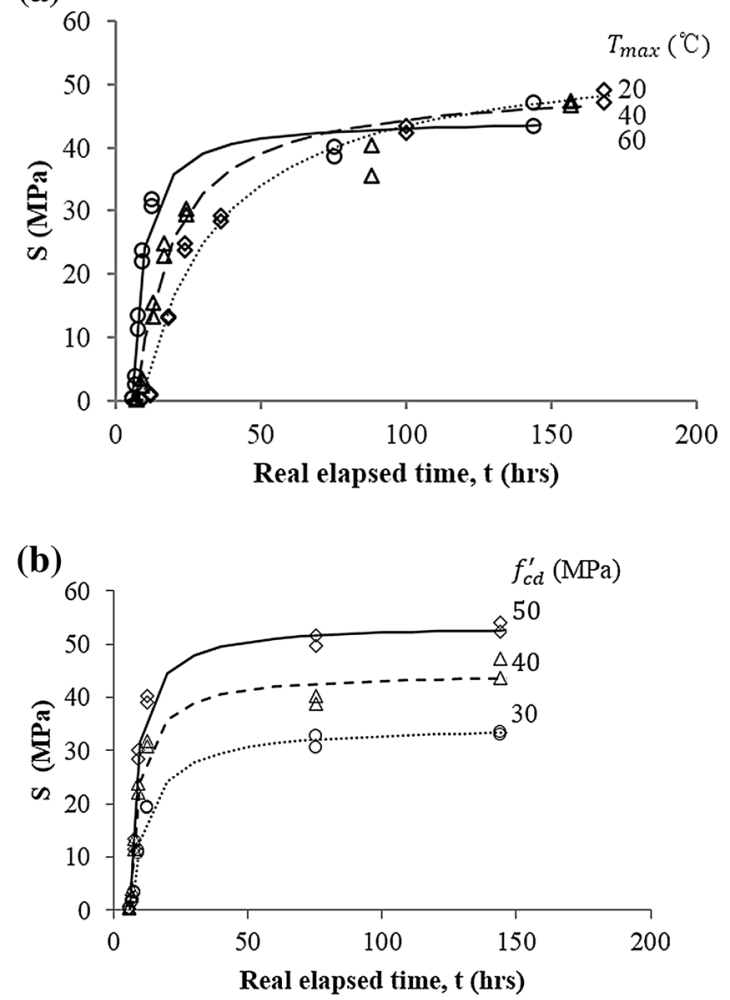

Fig. 3 Effect of $T_{\max }$ and $f_{\mathrm{cd}}^{\prime}$ on concrete strength development. a Effect of $T_{\max }$ on concrete strength development $\left(f_{\text {cd }}^{\prime}=40 \mathrm{MPa}\right)$. b Effect of compressive strength on concrete strength development $\left(T_{\max }=60^{\circ} \mathrm{C}\right)$.
In Eq. (2), the rate constant was adopted from the Arrhenius equation for concrete (Arrhenius 1889). The rate constant represents the number of collisions in a given time during the hydration reaction and is expressed as:

$$
k=A \cdot e^{-E /\left[R \cdot\left(T_{\mathrm{c}}+273\right)\right]}
$$

where, $A$ is the frequency factor $\left(\right.$ day $\left.^{-1}\right)$ and $E$ is the activation energy in general $(\mathrm{J} / \mathrm{mol})$.

Tank and Carino (1991) proposed Eq. (4) to estimate the relative strength increase of concrete in terms of $t_{\mathrm{eq}}$ with $r=2$ in Eq. (2):

$$
S=S_{\mathrm{u}} \frac{k_{\mathrm{r}}\left(t_{\mathrm{eq}}-t_{0 \mathrm{r}}\right)}{1+k_{\mathrm{r}}\left(t_{\mathrm{eq}}-t_{0 \mathrm{r}}\right)}
$$

where, $k_{\mathrm{r}}$ is the rate constant at reference temperature, $T_{\mathrm{r}}$ $\left(\right.$ day $\left.^{-1}\right)\left(=A \cdot e^{-E /\left[R \cdot\left(T_{\mathrm{r}}+273\right)\right]}\right)$ and $t_{0 \mathrm{r}}$ is the age at the start of strength development at the reference temperature (day).

Various attempts have been made to better predict strength development of concrete cured under different conditions by functionalizing the expressions for $r, A, E$, and $S_{\mathrm{u}}$ in Eqs. (2), (3) and (4) with some influential factors such as $T_{\mathrm{c}}$, $t, W / C$, humanity, chemical components, Blain value and degree of hydration (Freiesleben and Pedersen 1977; Carino 1991; Jonasson et al. 1995; Kim et al. 2001; Schindler 2004; Yi et al. 2005; Abdel-Jawad 2006; Poole 2006; Liao et al. 2008; Kwon et al. 2014).

In this study, Carino's model in Eq. (4) was adopted to predict the strength development of the ESC. The best-fitting 
coefficients of $t_{0 \mathrm{r}}, S_{\mathrm{u}}, A$ and $E$ in Eq. (4) were identified after performing separate regression analyses for fifteen different cases consisting of three concrete strengths (30, 40 and $50 \mathrm{MPa}$ ) cured at five different $T_{\max }$ of $20,30,40,50$ and $60{ }^{\circ} \mathrm{C}$. A constant value of $R=8.314 \mathrm{~J} / \mathrm{mol} / \mathrm{K}$ was used throughout this study. The effects of humidity, chemical components and Blaine value on the development of compressive strength of the ESC were considered negligible, since the ESC used in this study was all made with the same SHESC produced by the same company, and all tests were performed under the relative humidity at $50 \pm 5 \%$.

Case I in Table 3 summarizes the best-fitting values as well as the average $(\mu)$ and standard deviation $(\sigma)$ of the ratios of predicted strengths to experimentally observed strengths for $t_{\mathrm{eq}}>t_{0 r}$. Comparisons between predictions and experimental results on the developed compressive strengths indicated that significant overestimations were made by the model in early-stage curing before $t_{\text {eq }}$ of $18 \mathrm{~h}$ (Fig. 4a). These overestimations resulted in large values of $\mu$ with relatively large $\sigma$ (Case I in Table 3).

Based on the regression results given in Case I in Table 3, namely that the largest value of $A\left(1.01 \times 10^{7} \mathrm{day}^{-1}\right.$ for $\mathrm{CH} 40$ ) was only about 1.03 times greater than the smallest value $\left(0.99 \times 10^{7} \mathrm{day}^{-1}\right.$ for CL50), a constant value of $1.0 \times 10^{7}$ day $^{-1}$ was assumed in the following analyses. This agrees with the finding reported by Kim et al. (1998) and Yi et al. (2005). The results shown in Case I in Table 3 suggest that values of $t_{0 \mathrm{r}}$ in equivalent age also remained essentially the same - close to its average of $9.1 \mathrm{~h}$ (0.38 days) - regardless of different values of $f_{\mathrm{cd}}^{\prime} s$ and $T_{\max }$. This observation agrees in part with the findings made by Kim et al. (2001) that $t_{0 \mathrm{r}}$ does not depend on concrete strengths. A constant value of 0.38 day was, therefore, adopted for $t_{0 \mathrm{r}}$ in this study. The remaining parameters $\left(S_{\mathrm{u}}\right.$ and $\left.E\right)$ exhibited their dependency on concrete strength and $T_{\max }$.

As can be seen in Case I in Table 3, the values of $S_{\mathrm{u}}$ seemed to increase with increase in $f_{\mathrm{cd}}^{\prime}$ and decrease with increase in $T_{\max }$. This agrees with the observations made by other researchers (Tank and Carino 1991; Yi et al. 2005; Liao et al. 2008; Kwon et al. 2014). Values of $E$ tabulated in Case I in Table 3 show linearly decreasing tendency with increase in $T_{\max }$ for all concrete strengths, which agrees with the experimental observations made by Jonasson et al. (1995), Kim et al. (2001) and Yang et al. (2016). It can also be observed that $\mathrm{E}$ decreases with increase in $f_{\text {cd }}^{\prime}$ (or with decrease in $W / C$ ) at a given $T_{\max }$, which was also in agreement with previous observations made by Kim et al. (2001), Abdel-Jawad (2006) and Kwon et al. (2014).

Based on these observations, the following regression equations were suggested to evaluate $E$ and $S_{\mathrm{u}}$ in Eq. (3) and Eq. (4), respectively:

$$
\begin{gathered}
E\left(W / C, T_{\max }\right)=a_{\mathrm{e}} \times T_{\max }+b_{\mathrm{e}} \times W / C+c_{\mathrm{e}} \leq E_{\max } \\
S_{\mathrm{u}}\left(f_{\mathrm{cd}}^{\prime}, T_{\max }\right)= \\
S_{\mathrm{ur}}\left[\left(a_{\mathrm{s} 1} \times f_{\mathrm{cd}}^{\prime}-b_{\mathrm{s} 1}\right) \times T_{\max }\right. \\
\left.+a_{\mathrm{s} 2} \times f_{\mathrm{cd}}^{\prime}+b_{\mathrm{s} 2}\right] \leq S_{\mathrm{ur}}
\end{gathered}
$$

where, $a_{\mathrm{e}}=117.4 \times W / C-67.6 ; b_{\mathrm{e}}=2314 ; c_{\mathrm{e}}=39,214$, $E_{\max }$ is the experimentally measured value of $E$ with $T_{\max }$ and $W / C$ equal to $20^{\circ} \mathrm{C}$ and 0.46 , respectively $(=40,175 \mathrm{~J} / \mathrm{mol})$, $S_{\mathrm{ur}}=0.93 \times f_{\mathrm{cd}}^{\prime}+20.2, \quad a_{\mathrm{s} 1}=5.0 \times 10^{-5}, \quad b_{\mathrm{s} 1}=5.3 \times$ $10^{-3}, a_{\mathrm{s} 2}=1.2 \times 10^{-3}$ and $b_{\mathrm{s} 2}=1.0$.

Comparison between 210 experimental results and predictions made by the modified model with functionalized $S_{\mathrm{u}}$ and $E$ is shown in Fig. 4b, and its statistical parameters are given in Case II in Table 3. The $\mu$ and $\sigma$ of the ratios of the model predictions to experimentally measured values are 1.39 and 1.16, respectively. The predictions made in Case II were impaired by a large value of $\sigma$ at 1.16 . Comparisons of model predictions with test results revealed that it was mainly due to overestimations on the strength development at early-stage curing, before $18 \mathrm{~h}$. In order to improve the prediction on the early-stage strength development, a corrective function $\beta$ in terms of $t_{\mathrm{eq}}$ and $t_{0 \mathrm{r}}$ is introduced to Eq. (4). The final form of the generalized predictive equation for the development of compressive strength of ESC is given as Eq. (6). In Eq. (6), $A, R$ and $t_{0 \mathrm{r}}$ are given constant values of $1.0 \times 10^{7}$ day $^{-1}, 8.314 \mathrm{~J} / \mathrm{mol} / \mathrm{K}$ and 0.38 days, respectively. The expressions for $S_{\mathrm{u}}$ and $E$ from Eq. (5) were used in Eq. (6).

$$
S=S_{\mathrm{u}} \cdot \frac{1}{\beta} \cdot \frac{A \cdot e^{-E /\left[R \cdot\left(T_{\mathrm{r}}+273\right)\right]} \cdot\left(t_{\mathrm{eq}}-t_{0 \mathrm{r}}\right)}{1.0+A \cdot e^{-E /\left[R \cdot\left(T_{\mathrm{r}}+273\right)\right]} \cdot\left(t_{\mathrm{eq}}-t_{0 \mathrm{r}}\right)}
$$

where, $\quad \beta=1-\left[1-a_{\mathrm{r}} \cdot 24 \cdot\left(t_{\mathrm{eq}}-t_{0 \mathrm{r}}\right)\right] \times e^{-24 b_{\mathrm{r}} \cdot\left(t_{\mathrm{eq}}-t_{0 \mathrm{r}}\right)}$, $a_{\mathrm{r}}=0.3 \times f_{\mathrm{cd}}^{\prime}-7.7$ and $b_{\mathrm{r}}=9.6 \times 10^{-3} \times f_{\mathrm{cd}}^{\prime}+0.17$.

Figure $4 \mathrm{c}$ illustrates improved predictions made by Eq. (6) compared with previous ones in Figs. 4a, b. The $\mu$ and $\sigma$ for the ratios of model predictions to experimental findings were 0.99 and 0.20 , respectively (Case III in Table 3). The developed model seems to predict the test results with a reasonable accuracy.

\section{Optimization of Precast Prestressed Concrete with ESC}

In the following, the previously developed material model in Eq. (6) was used to find the optimized curing schedules for precast prestressed concrete members fabricated using ESC with $f_{\text {cd }}^{\prime}=30,40$ and $50 \mathrm{MPa}$, respectively.

\subsection{Formulation of Optimum Curing Regime}

In Fig. 5a, a typical 3-6-3 curing regime is illustrated with a 24-h turnover period. It consists of a 3-h preliminary work period for preparation and concrete casting followed by a $3-\mathrm{h}$ delay period before the initiation of steam curing, a 12-h steam curing period, a 3-h cooling period, and a 3-h posterior work period for cutting, demolding and transportation. The 12-h steam curing period comprises a 3-h temperature increase at a rate of $13.3{ }^{\circ} \mathrm{C} / \mathrm{h}$, a $6-\mathrm{h}$ constant $T_{\max }$ equal to $60{ }^{\circ} \mathrm{C}$, and a 3-h temperature decrease at a rate of $13.3{ }^{\circ} \mathrm{C} / \mathrm{h}$. When prestress is transferred at the end of cooling period, the concrete is expected to have developed $70 \%$ of $f_{\mathrm{cd}}^{\prime}$ value. 


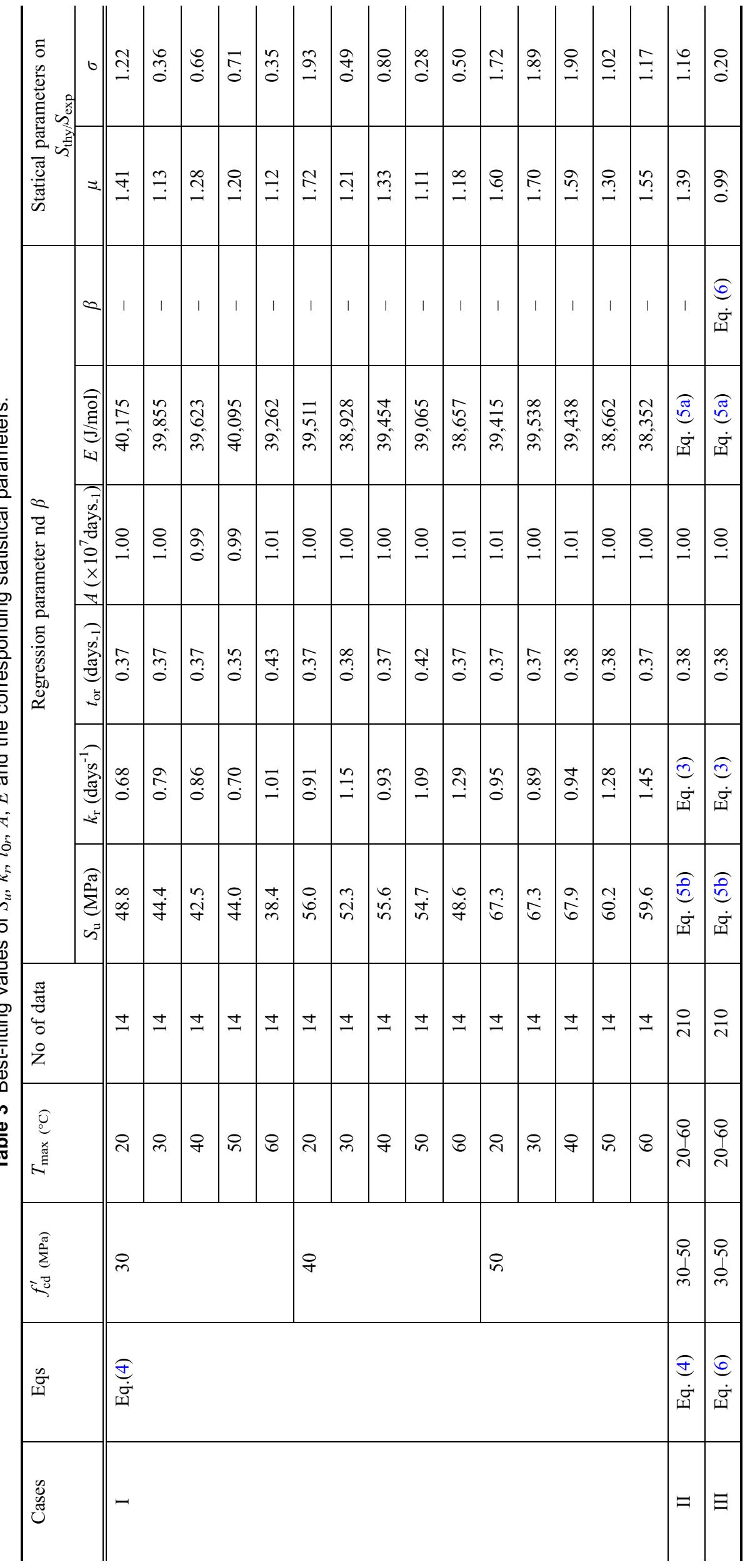


(a)

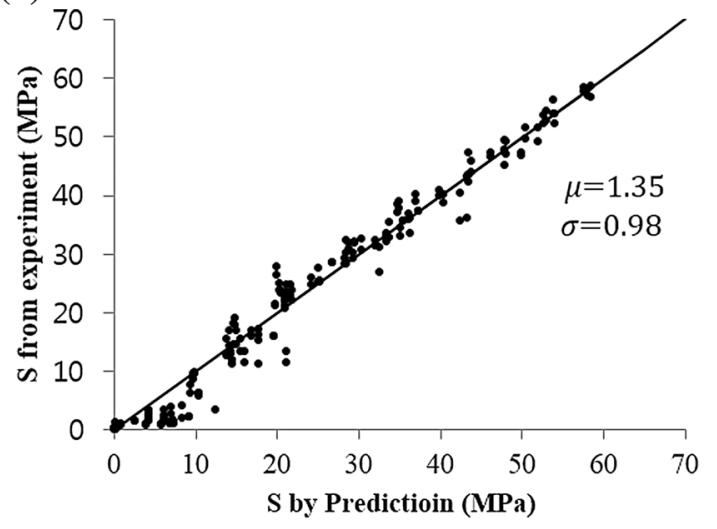

(b)

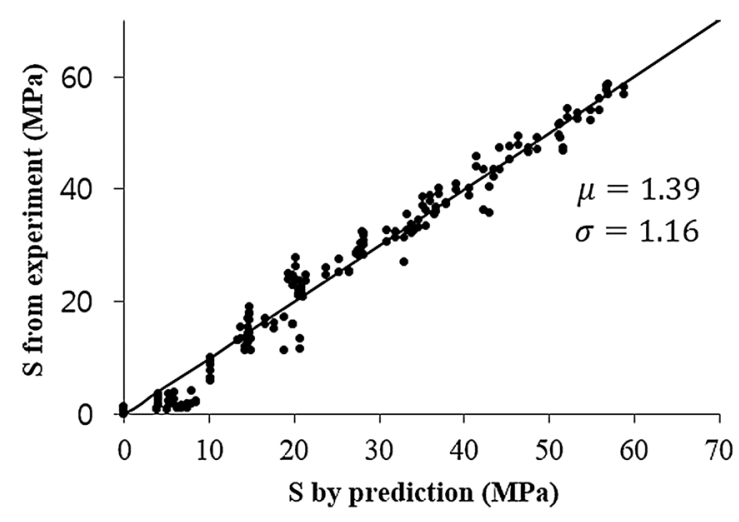

(c)

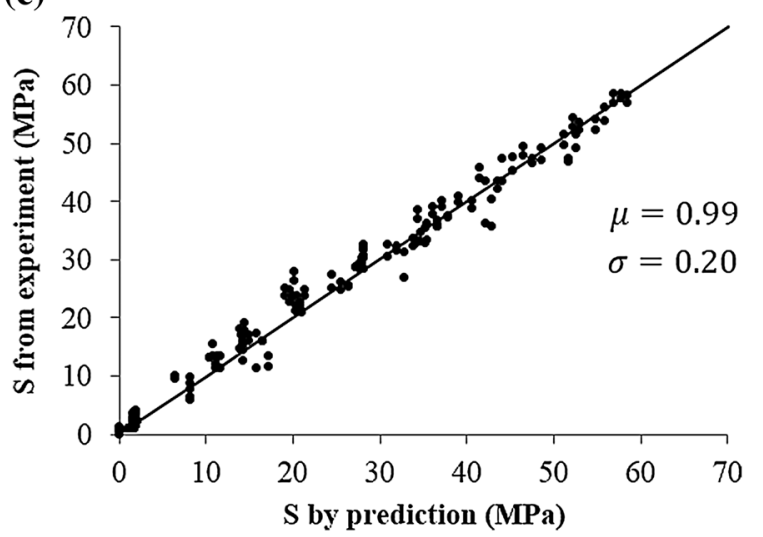

Fig. 4 Comparisons between model predictions and test results. a Case I. b Case II. c Case III.

This provides for sufficient bond strength to transfer the prestress to the surrounding concrete while ensuring that stresses in the concrete induced by the transferred prestress do not exceed the allowable stresses specified in the code provisions (Erdogdu and Kurbetci 1998; ACI318-11 2011).

The objective of this study is to find the optimized curing regime, which enables ESC to develop $70 \%$ of $f_{\text {cd }}^{\prime}$ value with minimum consumption of fuel within a given 24-h turnover period. For the purpose of measuring fuel consumption, the energy index $\left(E_{\mathrm{idx}}\right.$ in $\left.{ }^{\circ} \mathrm{C} / \mathrm{hr}\right)$ was calculated for each curing regime (Ramezanianpour et al. 2013). $E_{\mathrm{idx}}$ is defined as the total area under the curing time versus temperature curve during the elevated temperatures above $T_{\mathrm{r}}$ ( $20{ }^{\circ} \mathrm{C}$ in this study) (see Fig. 5a). According to this definition, the value of $E_{\mathrm{idx}}$ for a typical 3-6-3 curing regime $\left(E_{\mathrm{idx}}^{\mathrm{t}}\right)$ is estimated to be $360{ }^{\circ} \mathrm{C} / \mathrm{h}$.

In optimization of curing regime, all candidate regimes consist of a series of sub-periods within the 24-h turnover period: a 3-h preparation period followed by a 3-h delay period at ambient temperature of $20^{\circ} \mathrm{C}$ (from $t_{\mathrm{o}}$ to $t_{\mathrm{de}}$ in Fig. $5 \mathrm{~b}$ ), a temperature ascending period ( $t_{\mathrm{de}}$ to $t_{\mathrm{cs}}$ ), a constant $T_{\max }$ period ( $t_{\mathrm{cs}}$ to $t_{\mathrm{ce}}$ ), a temperature descending period $\left(t_{\mathrm{ce}}\right.$ to $\left.t_{\mathrm{e}}\right)$, and a cooling period $\left(t_{\mathrm{e}}\right.$ to $t_{\mathrm{f}}$ ). Since a rapid increase or decrease of the temperature could have a detrimental effect on the concrete material properties such as undesirable porosity or cracking (Alexanderson 1972), constraints were imposed against the rates of temperature increase $\left(k_{\mathrm{a}}\right)$ and decrease $\left(k_{\mathrm{d}}\right)$ so that $0{ }^{\circ} \mathrm{C} / \mathrm{h} \leq k_{\mathrm{a}} \leq 20^{\circ} \mathrm{C} / \mathrm{h}$ and $-20{ }^{\circ} \mathrm{C} / \mathrm{h} \leq k_{\mathrm{d}} \leq{ }^{\circ} \mathrm{C} / \mathrm{h}$, respectively, according to code recommendations (AASHTO 2004; PCA 2006).

It has been reported that a desirable $T_{\max }$ in steam curing for concrete made of Type I cement is in the range of 40 to $85^{\circ} \mathrm{C}$. At temperatures above $85^{\circ} \mathrm{C}$, long-term development of compressive strength and durability could be adversely affected (Türkel and Alabas 2005; Hwang et al. 2012). In this study, different upper bounds on $T_{\max }$ between 40 and $60{ }^{\circ} \mathrm{C}$ were considered and the corresponding values of $E_{\mathrm{idx}}$ were evaluated for the optimization process. In optimization, the value of $\mathrm{S}$ developed during 18-h curing period from the beginning of delay period $\left(t_{\mathrm{o}}\right)$ to the end of cooling period $\left(t_{\mathrm{f}}\right)$ is required to be greater than or equal to $0.7 f_{\mathrm{cd}}^{\prime}$.

In addition to the constraints given to the values of $S, k_{\mathrm{a}}, k_{\mathrm{d}}$ and $T_{\max }$, an additional constraint was imposed to prevent the occurrence of an incompatible curing regime. An incompatible curing regime could occur by an improper combination of design variables, for which the value of temperature obtained at the intersecting point of extending temperature increase and decrease lines $\left(T_{\text {its }}\right)$ becomes less than the value of $T_{\max }$ as shown in Fig. $5 \mathrm{c}$. If this happens, then $T_{\text {its }}$ needs to replace $T_{\max }$ for compatible curing regime. The objective function and all the constraints are presented in the following constrained optimization formulation: 
(a)

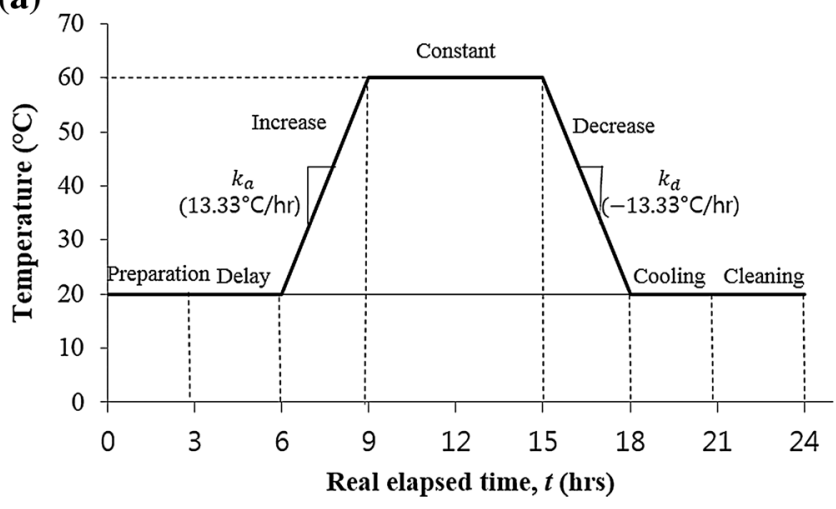

(b)

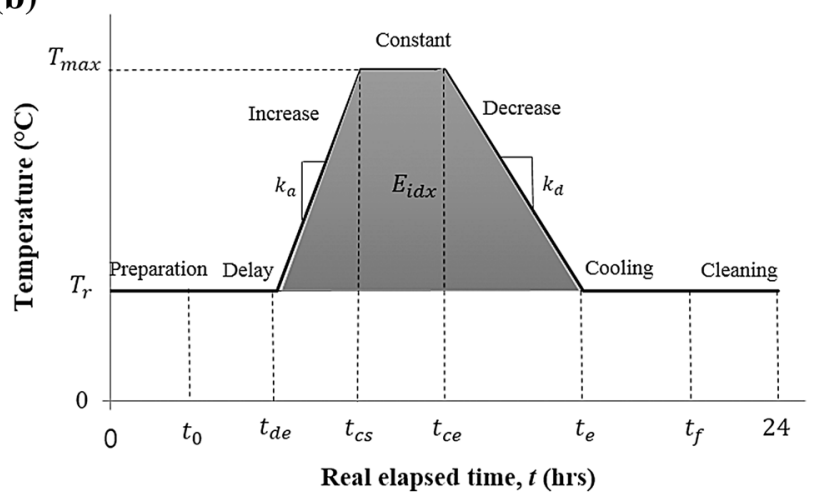

(c)

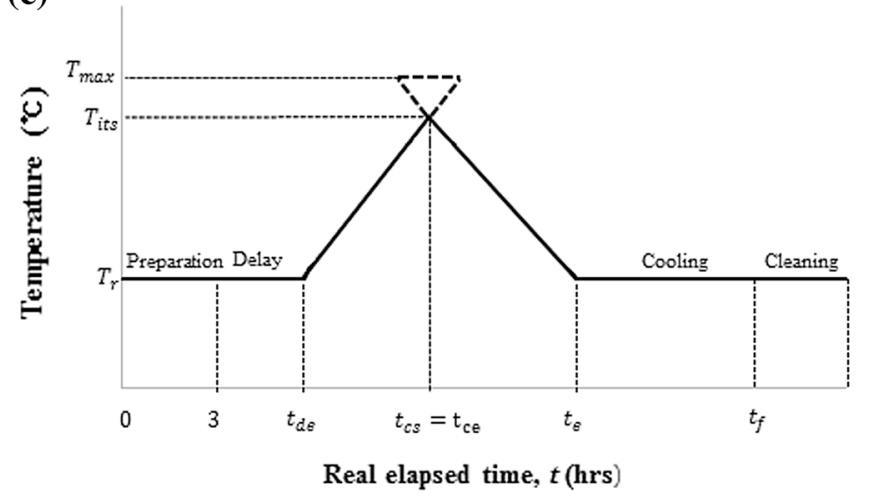

Fig. 5 Curing regimes a Typical 3-6-3 curing regime. b Optimized curing regime. $\mathbf{c}$ Incompatible curing regime.

Minimize $: E_{\mathrm{idx}}$

$$
\begin{aligned}
= & \left(T_{\mathrm{M}}-20\right)\left(t_{\mathrm{e}}-3\right)-\frac{\left(T_{\mathrm{M}}-20\right)^{2}}{2 \cdot k_{\mathrm{a}}} \\
& +\frac{\left(T_{\mathrm{M}}-20\right)^{2}}{2 \cdot k_{\mathrm{d}}}
\end{aligned}
$$

Subject to:

$$
\begin{aligned}
& T_{\mathrm{M}}=\text { smaller of }\left(T_{\max }, T_{\mathrm{its}}\right) ; \\
& 0.7 \cdot f_{\mathrm{cd}}^{\prime} \leq S \leq f_{\mathrm{cd}}^{\prime} \\
& t_{\mathrm{de}} \leq t_{\mathrm{e}} \leq t_{\mathrm{f}}
\end{aligned}
$$

$0{ }^{\circ} \mathrm{C} / \mathrm{h} \leq k_{\mathrm{a}} \leq 20^{\circ} \mathrm{C} / \mathrm{h}$; and $20^{\circ} \mathrm{C} / \mathrm{h} \leq k_{\mathrm{d}} \leq 0{ }^{\circ} \mathrm{C} / \mathrm{h}$. where, $T_{\max }=40,50$ or $60{ }^{\circ} \mathrm{C}$ and $T_{\text {its }}=20+k_{\mathrm{a}} \cdot\left(\frac{3 \cdot k_{\mathrm{a}}-k_{\mathrm{d}} \cdot t_{\mathrm{e}}}{k_{\mathrm{a}}-k_{\mathrm{d}}}-3\right)$.

Optimum curing regimes were found for ESC having $f_{\mathrm{cd}}^{\prime}$ the values of 30, 40 and $50 \mathrm{MPa}$. For each value of $f_{\mathrm{cd}}^{\prime}$, the values of four design variables $k_{\mathrm{a}}, T_{\mathrm{M}}, k_{\mathrm{d}}$ and $t_{\mathrm{e}}$ that minimize the value of $E_{\mathrm{idx}}$ in Eq. (7) were found for each of the $t_{\mathrm{f}}$ values $12,14,16$ and $18 \mathrm{~h}$. For each of the previous conditions, three different cases were considered with the temperature $T$ bounded between $20^{\circ} \mathrm{C}$ and the smaller value of $T_{\text {its }}$ and $T_{\max }$ values. Therefore, a total of 36 cases of candidate steam curing regimes were considered resulting from combinations of three values of $f_{\mathrm{cd}}^{\prime}$, four values of $t_{\mathrm{f}}$ and three values of $T_{\max }\left(=40,50\right.$ and $\left.60{ }^{\circ} \mathrm{C}\right)$.

In the preliminary search, a step-by-step method was used to find a set of discrete values of design variables leading to a near local minimum value of $E_{\mathrm{idx}}$ in Eq. (7). In implementing Eq. (7), four loops were used, where the value of a particular design variable was increased by a finite increment from its lowest value to highest value step-by-step. The values of $0.5,-0.5$ and $0.5{ }^{\circ} \mathrm{C} / \mathrm{h}$ were assigned as incremental values for $k_{\mathrm{a}}, k_{\mathrm{d}}$ and $t_{\mathrm{e}}$, respectively. An extensive number of searches were made in the domain of design variables for a specific optimization case with pre-assigned values of $f_{\mathrm{cd}}^{\prime}, t_{\mathrm{f}}$ and $T_{\max }$. These values leading to the near local minimum value of $E_{\text {idx }}$ were then saved.

In the subsequent search, values of design variables found from the preliminary search were further refined by using a nonlinear searching technique. For this, Eq. (7) was transformed to an unconstrained optimization formulation using the penalty terms as given in Eq. (8).

$$
\begin{aligned}
\text { Minimize } & : F \\
= & W_{E} \cdot r_{\mathrm{idx}} \\
& +\frac{1}{6} \sum_{i=1}^{6}\left[W_{i} \cdot\left(\frac{x_{i}}{x_{i}^{m}}-\frac{x_{i}^{L}}{x_{i}^{m}}+\frac{x_{i}^{U}}{x_{i}^{m}}-\frac{x_{i}^{2}}{x_{i}^{m}}\right)\right]
\end{aligned}
$$

where, $W_{E}$ and $W_{\mathrm{i}}$ are the weights given to $r_{\mathrm{idx}}$ and the $i$-th penalty, respectively $(i=1,2, \ldots, 6), r_{\mathrm{idx}}=E_{\mathrm{idx}} / E_{\mathrm{idx}}^{\mathrm{t}},\langle v\rangle=$ $\left\{\begin{array}{c}0 \text { if } v \leq 0 \\ v \text { if } v>0\end{array}\right.$ and $x_{\mathrm{i}}, x_{i}^{L}, x_{i}^{U}$ and $x_{i}^{m}$ are the $i$-th design variable, its lower and upper bounds and its median values, respectively, as tabulated in Table 4. 
Table 4 Lower, upper and medium values of design variables.

\begin{tabular}{|c|c|c|c|c|}
\hline$i$ & $x_{i}$ & $x_{i}^{L}$ & $x_{i}^{U}$ & $x_{i}^{m}$ \\
\hline \multirow[t]{3}{*}{1} & \multirow[t]{3}{*}{$T_{\max }\left({ }^{\circ} \mathrm{C}\right)$} & \multirow[t]{3}{*}{ For all cases, $T_{r(=20)}$} & 40 for $T_{\max }=40$ & 10 \\
\hline & & & 50 for $T_{\max }=50$ & 15 \\
\hline & & & 60 for $T_{\max }=60$ & 20 \\
\hline \multirow[t]{3}{*}{2} & \multirow[t]{3}{*}{$S(\mathrm{MPa})$} & 21 for $f_{\mathrm{cd}}^{\prime}=30$ & 30 & 25.5 \\
\hline & & 28 for $f_{\mathrm{cd}}^{\prime}=40$ & 40 & 34.0 \\
\hline & & 35 for $f_{\mathrm{cd}}^{\prime}=50$ & 50 & 42.5 \\
\hline \multirow[t]{4}{*}{3} & \multirow[t]{4}{*}{$t_{\mathrm{e}}(\mathrm{h})$} & \multirow[t]{4}{*}{ For all cases, 3} & 12 for $t_{\mathrm{f}}=12$ & 4.5 \\
\hline & & & 14 for $t_{\mathrm{f}}=14$ & 5.5 \\
\hline & & & 16 for $t_{\mathrm{f}}=16$ & 6.5 \\
\hline & & & 18 for $t_{\mathrm{f}}=18$ & 7.5 \\
\hline 4 & $k_{\mathrm{a}}\left({ }^{\circ} \mathrm{C} / \mathrm{h}\right)$ & For all cases, 0 & For all cases, 20 & For all cases, 10 \\
\hline 5 & $k_{\mathrm{d}}\left({ }^{\circ} \mathrm{C} / \mathrm{h}\right)$ & For all cases, - 20 & For all cases, 0 & For all cases, - 10 \\
\hline \multirow[t]{3}{*}{6} & \multirow[t]{3}{*}{$T_{\text {its }}\left({ }^{\circ} \mathrm{C}\right)$} & 40 for $T_{\max }=40$ & \multirow[t]{3}{*}{ For all cases, $T_{\text {its }}$} & 10 \\
\hline & & 50 for $T_{\max }=50$ & & 15 \\
\hline & & 60 for $T_{\max }=60$ & & 20 \\
\hline
\end{tabular}

The Powell's algorithm was applied to Eq. (8), which converges to a global minimum in $\mathrm{n}$ number of searches for n-dimensional quadratic functions (Powell 1964). The Powell's method is preferred in minimizing Eq. (8) as it has quadratic terms in its formulation, and also because the method does not require gradients of a given function. The design variable values obtained from the first level of searches were used as initial values in the Powell's algorithm. After refinement by the subsequent search, the values of $E_{\text {idx }}$ in Eq. (7) from the preliminary searches were further reduced only by $2.0 \%$ or less.

From preliminary and subsequent searches, it was consistently observed that the constraints on $T$ and $k_{\mathrm{a}}$ became near active or active at their upper bound values for all cases with differing values of $f_{\text {cd }}^{\prime}, T_{\max }$ and $t_{\mathrm{f}}$. This was because ESC reaches higher compressive strength more effectively under the rapidly increased higher temperature during the early stage of curing. Based on this observation, the values of upper bound for $T$ and $k_{\mathrm{a}}$ were fixed to their maximum values $\left(T=T_{\max }\right.$ and $\left.k_{\mathrm{a}}=20^{\circ} \mathrm{C} / \mathrm{h}\right)$, and the optimized design values of $k_{\mathrm{d}}$ and $t_{\mathrm{e}}$ were searched again from Eq. (8) using the Powell's method. This further refined the values of $k_{\mathrm{d}}$ and $t_{\mathrm{e}}$ but resulted in the marginally reduced value of $E_{\mathrm{idx}}$.

\subsection{Results of Optimization}

As the difference was marginal in the optimized values of $E_{\text {idx }}$ by the discrete step-by-step search and by the Powell's method, discrete design values from the step-by-step search were presented in Table 5 for practical purpose. In Table 5, the results of optimization obtained for different values of $f_{\text {cd }}^{\prime}, T_{\max }$ and $t_{\mathrm{f}}$ were listed. For each case, values of optimized design variables as well as the corresponding values of $\mathrm{S}$ in terms of $\mathrm{S} / 0.7 f_{\mathrm{cd}}^{\prime}$ and $r_{\mathrm{idx}}$ were also tabulated. The values of $r_{\mathrm{idx}}$ in Table 5 show that for all values of $f_{\mathrm{cd}}^{\prime}$, the optimized values of $E_{\mathrm{idx}}$ for ESC are 23 to $57 \%$ less than those from the typical 3-6-3 curing regime for concrete made of Type I cement.

More reduction in Eidx was realized for ESC with higher $f_{\text {cd }}^{\prime}$ than with lower $f_{\text {cd }}^{\prime}$ under the same $T_{\max }$ and $t_{\mathrm{f}}$ values. The largest reduction in $E_{\mathrm{idx}}$ was realized for all $f_{\mathrm{cd}}^{\prime}$ with $T_{\max }=60{ }^{\circ} \mathrm{C}$ and $t_{\mathrm{f}}=18 \mathrm{~h}$. The values of $r_{\mathrm{idx}}$ are 0.59 , 0.52 and 0.43 for $f_{\mathrm{cd}}^{\prime}=30,40$ and $50 \mathrm{MPa}$, respectively.

The values of $r_{\mathrm{idx}}$ from optimized regimes in Table 5 indicate that lower fuel consumption can be realized by allowing a longer cooling period with a greater value of $t_{\mathrm{f}}$. This was because an additional increase in concrete strength can be attained during an extended cooling period without fuel consumption. As the upper bound of $T$ was lowered from $T_{\max }=60 \mathrm{C}$ to $40{ }^{\circ} \mathrm{C}$, a longer period with a larger value of $t_{\mathrm{f}}$ was needed. For this case, however, a feasible design with sufficient concrete strength was available only with the longest period of $t_{\mathrm{f}}=18 \mathrm{~h}$ for all $f_{\mathrm{cd}}^{\prime} s$.

In Fig. 6(a), the optimum curing regimes with the lowest value of $E_{\mathrm{idx}}$ obtained from the condition of $T_{\max }=60 \mathrm{C}$ and $t_{\mathrm{f}}=18 \mathrm{~h}$ are presented for each $f^{\prime}$ cd value with the corresponding development of compressive strength of ESC based on Eq. (6). Because a higher increase rate of $k_{\mathrm{a}}=20 \mathrm{C} / \mathrm{hr}$ was adopted in the optimized regime, a rather rapid increase in compressive strength in the ESC was observed from 3 to $5 \mathrm{~h}$ after increasing temperature. After $8 \mathrm{~h}$ of curing, more than $50 \%$ of $0.7 f_{\mathrm{cd}}^{\prime}$ was developed by the optimized regimes for all $f_{\mathrm{cd}}^{\prime}$ values. The rate of strength increase was then decreased and the strength gradually approached the target strength of $0.7 f_{\mathrm{cd}}^{\prime}$ during the temperature decrease and cooling periods after a constant $T_{\max }$ period. The optimized values of $E_{\mathrm{idx}}\left(r_{\mathrm{idx}}\right)$ were $211.5(0.59)$, 


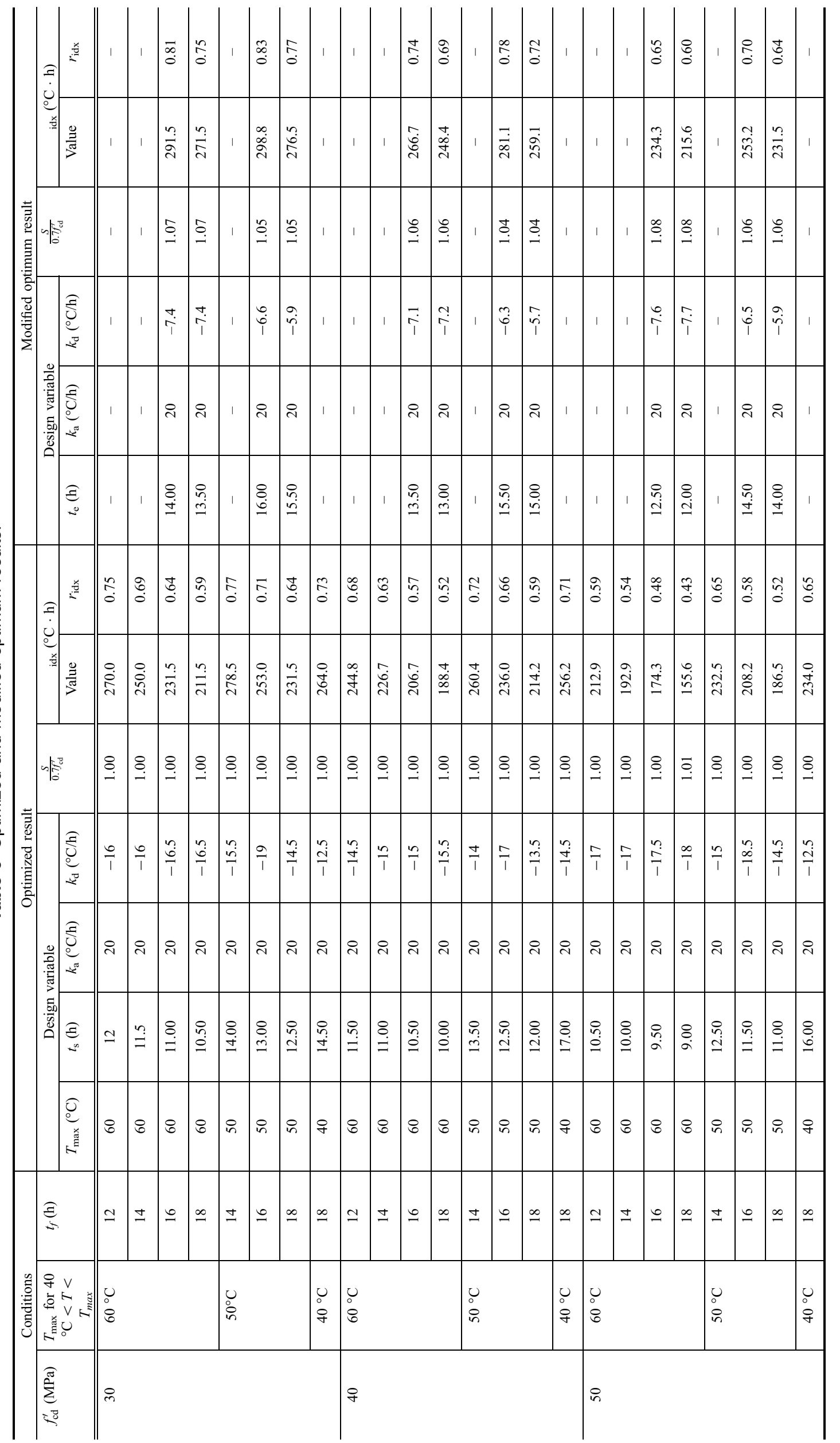



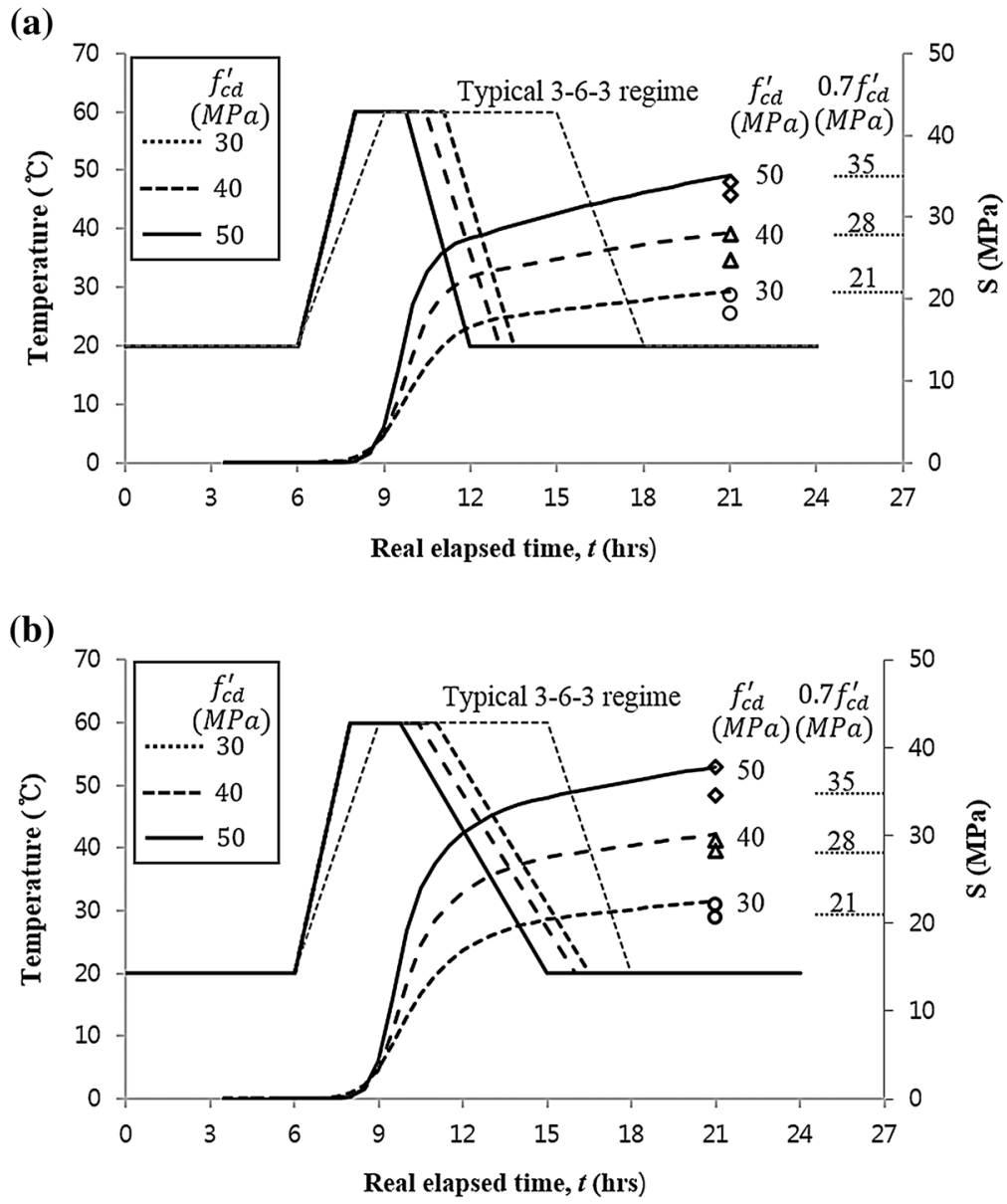

Fig. 6 Optimum and modified curing regimes and the corresponding concrete strength developments (circle, triangle and diamond $=$ measured $\mathrm{S}$ for $f_{\mathrm{cd}}^{\prime}=30,40$ and $50 \mathrm{MPa}$, respectively), a Optimized curing regimes. b Modified optimum curing regimes.

$188.4(0.52)$ and $155.6 \mathrm{C} / \mathrm{h}(0.43)$ for $f_{\mathrm{cd}}^{\prime}$ equal to 30,40 and $50 \mathrm{MPa}$, respectively.

Figure $7 \mathrm{a}$ illustrates the effects of $t_{\mathrm{f}}$ on $E_{\mathrm{idx}}$ when $T_{\max }=60$. As can be seen in Fig. $7 \mathrm{a}$, for all values of $f_{\mathrm{cd}}^{\prime}$, the values of $E_{\mathrm{idx}}$ are shown to decrease almost linearly with the increase in the values of $t_{\mathrm{f}}$. As explained earlier, it was mainly due to the additional strength gain during an extended cooling period without fuel consumption at ambient temperature of $20{ }^{\circ} \mathrm{C}$ after early-stage rapid strength increase at elevated temperature.

Figure $7 \mathrm{a}$ also shows that more reduction of $E_{\text {idx }}$ can be realized for a greater $f_{\mathrm{cd}}^{\prime}$ value at the same values of $t_{\mathrm{f}}$. This is attributed to a more rapid increase in strength development for ESC with higher compressive strength at the same $T_{\max }$ as shown in Figs. 3 and 6.

Figure $7 \mathrm{~b}$ shows the effects of limiting the maximum value of $T\left(T_{\max }\right)$ on the $E_{\mathrm{idx}}$ value. Given a value of $t_{\mathrm{f}}=18 \mathrm{~h}$, the curing regime with a higher $T_{\max }$ became more efficient, resulting in a smaller value of $E_{\mathrm{idx}}$ for all. As can be seen in Table 5, a larger amount of $E_{\mathrm{idx}}$ was reduced at lower $T_{\max }$ as the value of $t_{\mathrm{f}}$ increased for all $f_{\mathrm{cd}}^{\prime}$. This is because a longer period with an elevated temperature is needed for ESC to sufficiently develop its early strength with (a)

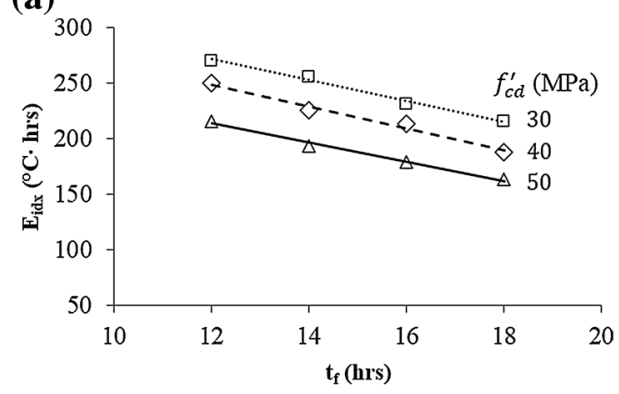

(b)

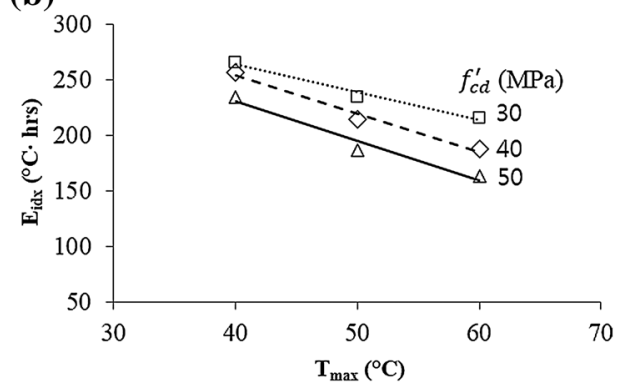

Fig. 7 Effects of $t_{\mathrm{f}}, f_{\mathrm{cd}}^{\prime}$ and $T_{\max }$ on $E_{\mathrm{idx}}$. a Effects of $t_{\mathrm{f}}$ and $f_{\mathrm{cd}}^{\prime}$ on $E_{\mathrm{idx}}\left(T_{\max }=60^{\circ} \mathrm{C}\right)$. b Effects of $T_{\max }$ on $E_{\mathrm{idx}}$ $\left(t_{\mathrm{f}}=18 \mathrm{~h}\right)$. 
a relatively lower $T_{\max }$ than a higher $T_{\max }$ so that its strength can reach $0.7 f_{\mathrm{cd}}^{\prime}$ with an additional strength gain during the subsequent cooling period.

\subsection{Verification and Modification of Optimum Curing Regimes}

Additional compression tests were performed for three sets of ESC with $f_{\text {cd }}^{\prime}$ equal to 30,40 and $50 \mathrm{MPa}$ to verify the proper development of compressive strength of the ESC when the optimized curing regimes as illustrated in Fig. 6a were applied. The same curing method and mix proportion were used as described for the 210 compression tests in previous sections. Two cylinders of $100 \times 200 \mathrm{~mm}$ from the same batch were tested in compression for each $f_{\mathrm{cd}}^{\prime}$ value. The results are shown in Fig. 6a. The averages of the ratio of $\mathrm{S} / 0.7 f_{\text {cd }}^{\prime}$ were less than 1.0 , showing $0.92,0.94$ and 0.96 for $f_{\text {cd }}^{\prime}$ equal to 30,40 and $50 \mathrm{MPa}$, respectively. This might be due to statistical variety related to $\mu(=0.99)$ and $\sigma(=0.20)$ for the ratios of model predictions to experimental findings (see Case III in Table 3). Modified optimum curing regimes were then suggested by increasing the values of the optimized $t_{\mathrm{e}}$ by $3 \mathrm{~h}$. Increase in $t_{\mathrm{e}}$ was preferred than increasing the curing period related to $T_{\max }$ because it may need a less fuel consumption for the same amount of additional increase in $E_{\text {idx }}$. In Fig. 6b, modified curing regimes were illustrated. Predicted strength ratios of $\mathrm{S} / 0.7 f_{\mathrm{cd}}^{\prime}$ were $1.07,1.06,1.08$ for $f_{\text {cd }}^{\prime}$ equal to 30,40 and $50 \mathrm{MPa}$, respectively. From the additional compression tests performed on two cylinders for each $f_{\text {cd }}^{\prime}$ cured under the modified regimes, the averages of the ratio of $\mathrm{S} / 0.7 f_{\mathrm{cd}}^{\prime}$ were observed to be $1.02,1.03$ and 1.03 for $f_{\text {cd }}^{\prime}$ equal to 30,40 and $50 \mathrm{MPa}$, respectively. The values of $E_{\mathrm{idx}}\left(r_{\mathrm{idx}}\right)$ from the modified optimum curing regimes were $271.5(0.75), 248.4(0.69)$ and $215.6 \mathrm{C} / \mathrm{h}(0.60)$ for $f_{\mathrm{c}}$ equal to 30,40 and $50 \mathrm{MPa}$, respectively.

In Table 5, the values of design variables for the modified curing regime and the corresponding values of relative strength development $\left(\mathrm{S} / 0.7 f_{\mathrm{cd}}^{\prime}\right), E_{\mathrm{idx}}$ and $r_{\mathrm{idx}}$ are presented. The modified curing regimes were provided for $f_{\mathrm{cd}}^{\prime}$ values in the range of 30 to $50 \mathrm{MPa}$ and the upper bound of $T$ between $T_{\max }=50^{\circ} \mathrm{C}$ and $60 \mathrm{C}$. The cases either with $T_{\max }=40 \mathrm{C}$ or $t_{\mathrm{f}} \leq 14 \mathrm{~h}$ were excluded as their $E_{\mathrm{idx}}$ values were found to be relatively large compared with those from higher $T_{\max }$ and $t_{\mathrm{f}}$ values (see Table 5). Different value of $t_{\mathrm{f}}$ with $16 \mathrm{~h}$ or $18 \mathrm{~h}$ can be applied depending on the given value of $T_{\max }$.

Although the modified optimum regimes became less effective in $E_{\mathrm{idx}}$ than the optimum ones at the price of conservatism, they still save energy by 25,31 and $40 \%$ for $f_{\mathrm{cd}}^{\prime}=30,40$ and $50 \mathrm{MPa}$, respectively, for 24-turnover period (or $t_{\mathrm{f}}=18 \mathrm{~h}$ ) compared with those by typical 3-6-3 curing regimes (Table 5).

\section{Conclusions}

Previous studies in other literatures suggested the optimum curing regimes based on a number of trial curing regimes. In this study, however, optimum curing regimes were obtained from optimization technique with the generalized rate constant material model incorporating the concept of equivalent age for ESC. The following conclusions were made from this study.

(1) Based on the regression analyses of the data from the 210 compression tests, a generalized rate constant model for the prediction of strength development of ESC under different $T_{\max }$ was developed by functionalizing $S_{\mathrm{u}}$ and $E$. The $\mu$ and $\sigma$ for the ratios of predicted values to experimentally observed values were 0.99 and 0.20 , respectively.

(2) The optimization results based on the developed material model of ESC indicated that a more reduction in $E_{\mathrm{idx}}$ could be realized for ESC with: a higher $f_{\mathrm{cd}}^{\prime}$ under the same $T_{\max }$ and $t_{\mathrm{f}}$ values; a higher $T_{\max }$ and the greatest rate of temperature increase of $k_{\mathrm{a}}$ equal to $20{ }^{\circ} \mathrm{C} / \mathrm{h}$ for given $f_{\mathrm{cd}}^{\prime}$ and $t_{\mathrm{f}}$ values; and a greater value of $t_{\mathrm{f}}$ for given $f_{\mathrm{cd}}^{\prime}$ and $T_{\max }$ values.

(3) The largest reduction in $E_{\mathrm{idx}}$ was realized for all $f_{\mathrm{cd}}^{\prime}$ with $T_{\max }=60^{\circ} \mathrm{C}$ and $t_{\mathrm{f}}=18 \mathrm{~h}$. The values of $r_{\mathrm{idx}}$ were $0.59,0.52$ and 0.43 for $f_{\mathrm{cd}}^{\prime}=30,40$ and $50 \mathrm{MPa}$, respectively.

(4) Modification of the optimum regimes, however, was needed as the verification tests showed that the compressive strengths of cylinders obtained from the optimum regimes were 4-8\% less than the required strength of $0.7 f_{\text {cd }}^{\prime}$ due to inherent statistical variety related to model predictions.

(5) Modified optimum curing regimes were suggested by increasing the values of the optimized $t_{\mathrm{e}}$ by $3 \mathrm{~h}$. From the additional verification tests, the measured relative strengths of $\mathrm{S} / 0.7 f_{\mathrm{cd}}^{\prime}$ from modified curing regimes resulted in slightly conservative values of $1.02,1.03$ and 1.03 for $f_{\text {cd }}^{\prime}$ equal to 30,40 and $50 \mathrm{MPa}$, respectively.

(6) The modified regimes, although less effective in $E_{\mathrm{idx}}$ than the optimum ones at the price of conservatism, could reduce $E_{\text {idx }}$ by 25,31 , and $40 \%$ for 24-turnover period, compared with those from a typical 3-6-3 regime for $f_{\mathrm{cd}}^{\prime}=30,40$ and $50 \mathrm{MPa}$, respectively.

\section{Acknowledgments}

This research was supported by the Basic Science Research Program through the National Research Foundation of Korea (NRF) funded by the Ministry of Education, Science and Technology (NRF-2013R1A2A2A01011563).

\section{Open Access}

This article is distributed under the terms of the Creative Commons Attribution 4.0 International License (http://creativecommons.org/licenses/by/4.0/), which permits unrestricted use, distribution, and reproduction in any medium, provided you give appropriate credit to the original author(s) and the source, provide a link to the Creative Commons license, and indicate if changes were made. 


\section{References}

AASHTO 2004. (2004). A policy on geometric design of highways and streets.

Abdel-Jawad, Y. A. (2006). Estimating concrete strength using a modified maturity model. In Proceedings of the Institution of Civil Engineers, UK, Construction Materials (pp. 33-37).

ACI 517.2-2R-87. (1992). Accelerated curing of concrete at atmospheric pressure-state of the Art, ACI manual of concrete.

ACI 318-11. (2011). Building code requirements for structural concrete and commentary, ACI manual of concrete.

Alexander, K. M., \& Taplin, J. H. (1962). Concrete strength, paste strength, cement hydration and the maturity rule. Australian Journal of Applied Science, 13, 277-284.

Alexanderson, J. (1972). Strength losses in heat cured concrete, Swedish Cement Concrete. In Institute Proceedings.

Arrhenius, S. (1889). Über die reaktionsgeschwindigkeit bei der inversion von rohrzucker durch sauren. Zeitschrift für Physikalische Chemie, 4, 226-248.

ASTM C1074-04. (2004). Standard practice for estimating concrete strength by the maturity method.

ASTM C143/C143M-10. (2010). Standard test method for slump of hydraulic-cement concrete.

ASTM C231/231M-14. (2014) Standard test method for air content of freshly mixed concrete by the pressure method.

Bernhardt, C. J. (1956). Hardening of concrete at different temperatures. In RILEM symposium on winter concreting, copenhagen, Danish, Institute for Building Research, Session B-II.

Carino, N. J. (1991). The maturity method. In V. M. Malhotra \& N. J. Carino (Eds.), Handbook on nondestructive testing of concrete. Boca Raton, FL: CRC Press.

Carino, N. J., \& Lew, H. S. (1981). Temperature effects on the strength-maturity relations of mortars. ACI Journal Proceedings, 80, 177-182.

Erdogdu, S., \& Kurbetci, S. (1998). Optimum heat treatment cycle for cements of different type and composition. $\mathrm{Ce}$ ment and Concrete Research, 28, 1595-1604.

Freiesleben, H. B., \& Pedersen, E. J. (1977). Maturity computer for controlled curing and hardening of concrete. Nordisk Betong, 1, 21-25.

Hanson, J. A. (1963). Optimum steam curing procedure in precasting plants. ACI Journal, 60, 75-100.

Hwang, S. D., Khatib, R., Lee, H. K., Lee, S. H., \& Khayat, K. H. (2012). Optimization of steam-curing regime for highstrength, self-consolidating concrete for precast, prestressed concrete applications. PCI Journal, 57, 2-16.

Jonasson, J. E., Groth, P. \& Hedlund, H. (1995). Modeling of temperature and moisture field in concrete to study early age movements as a basis for stress analysis. In Proceedings of the international RILEM symposium on thermal cracking in concrete at early ages (pp. 45-52).

Kim, J. K., Han, S. H., \& Lee, K. W. (2001). Estimation of compressive strength by a new apparent activation energy function. Cement and Concrete Research, 31, 1761-1773.

Kim, J. K., Moon, Y. H., \& Eo, S. H. (1998). Compressive strength development of concrete with different curing time and temperature. Cement and Concrete Research, 28, 1761-1773.

Kjellsen, K. O., \& Detwiler, R. J. (1993). Later-age strength prediction by a modified maturity model. ACI Material Journal, 90, 220-227.

Kjellsen, K. O., Detwiler, R. J., \& Gjorv, O. E. (1990). Pore structure of plain cement pastes hydrated at different temperatures. Cement and Concrete Research, 20, 927-933.

Kwon, S. H., Jang, K. P., Bang, J. W., Lee, J. H., \& Kim, Y. Y. (2014). Prediction of concrete compressive strength considering humidity and temperature in construction of nuclear power plants. Nuclear Engineering and Design, 275, 23-29.

Liao, W. C., Lee, B. J., \& Kang, C. W. (2008). A humidity-adjusted maturity function for the early age strength prediction of concrete. Cement and Concrete Composite, 30, 515-523.

McIntosh, J. D. (1956). The effects of low-temperature curing on the compressive strength of concrete. In RILEM symposium on winter concreting, Copenhagen, Danish, Institute for Building Research, Session BII.

PCA (Portland Cement Association). (2006). Design and control of concrete mixtures. Skokie, IL: PCA.

Poole, J. L. (2006). Modeling temperature sensitivity and heat evolution of concrete, Ph.D. Dissertation of University of Texas at Austin.

Powell, M. J. (1964). An efficient method for finding the minimum of a function of several variables without calculating derivatives. The Computer Journal, 7, 155-162.

Ramezanianpour, A. A. M., Esmaeili, M., Ghahari, S. A., \& Najafi, M. H. (2013). Laboratory study on the effect of polypropylene fiber on durability, and physical and mechanical characteristic of concrete for application in sleepers. Construction and Building Materials, 44, 411-418.

Sajedi, F., \& Razak, H. A. (2011). Effects of curing regimes and cement fineness on the compressive strength of ordinary Portland cement mortars. Construction and Building Materials, 25, 2036-2045.

Schindler, A. K. (2004). Effect of temperature on hydration of cementitious materials. ACI Material Journal, 101, 72-81.

Schindler, A. K., \& Folliard, K. J. (2005). Heat of hydration models for cementitious materials. ACI Material Journal, 102, 24-33.

Tank, R. C., \& Carino, N. J. (1991). Rate constant functions for strength development of concrete. ACI Material Journal, $88,74-83$.

Türkel, S., \& Alabas, V. (2005). The effect of excessive steam curing on portland composite cement concrete. Cement and Concrete Research, 35, 405-411.

Verbeck, G. J. \& Helmuth, R. H. (1968). Structure and physical properties of cement paste. In Proceedings, fifth international symposium on the chemistry of cement (pp. 1-32).

Yang, K. H., Mun, J. S., Kim, D. G., \& Cho, M. S. (2016). Comparison of Strength-Maturity Models Accounting for Hydration Heat in Massive Walls. International Journal of Concrete Structures and Materials, 10(1), 47-60.

Yi, S. T., Moon, Y. H., \& Kim, J. K. (2005). Long-term strength prediction of concrete with curing temperature. Cement and Concrete Research, 35, 1961-1969. 